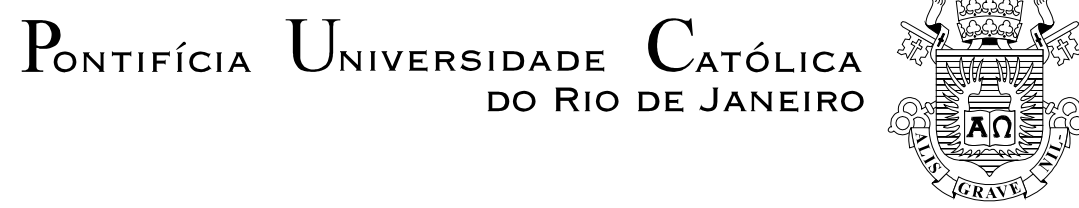

Diogo Vinícius Rosas Marinho

Algumas aplicações práticas de sistemas lineares e matrizes.

Dissertação de Mestrado

Dissertação apresentada como requisito parcial para obtenção do grau de Mestre pelo Programa de PósGraduação em Matemática, do Departamento de Matemática da PUC-Rio.

Orientadora: Profa. Renata Martins da Rosa

Rio de Janeiro Setembro de 2020 


$$
\text { Pontifícia Universidade } \text { Católica }_{\text {do Rio de Janeiro }}
$$

Diogo Vinícius Rosas Marinho

\section{Algumas aplicações práticas de sistemas lineares e matrizes.}

Dissertação apresentada como requisito parcial para obtenção do grau de Mestre pelo Programa de Pós-Graduação em Matemática da PUCRio. Aprovada pela Comissão Examinadora abaixo:.

Profa. Renata Martins da Rosa

Orientadora

Departamento de Matemática - PUC-Rio

Prof. Miguel Schnoor

Departamento de Matemática do ICEx-UFF

Profa. Tatiana Sodero

Departamento de Matemática - PUC-Rio

Prof. Sinesio Pesco

Departamento de Matemática - PUC-Rio

Rio de Janeiro, 10 de setembro de 2020 
Todos os direitos reservados. É proibida a reprodução total ou parcial do trabalho sem autorização da universidade, do autor e da orientadora.

\section{Diogo Vinícius Rosas Marinho}

Graduou-se em Engenharia de Fortificação e Construção pelo Instituto Militar de Engenharia. Atou em diversos cursos prémilitares desde 2003. Atualmente trabalha como engenheiro autônomo.

Marinho, Diogo Vinícius Rosas

Algumas aplicações práticas de sistemas lineares e matrizes / Diogo Vinícius Rosas Marinho ; orientadora: Renata Martins da Rosa. $-2020$.

46 f. : il. color. ; $30 \mathrm{~cm}$

Dissertação (mestrado)-Pontifícia Universidade Católica do Rio de Janeiro, Departamento de Matemática, 2020.

Inclui bibliografia

1. Matemática - Teses. 2. Cadeias de Markov. 3. Sistemas lineares. 4. Matrizes. 5. Matriz de Leontief. 6. Álgebra linear. I. Rosa, Renata Martins da. II. Pontifícia Universidade Católica do Rio de Janeiro. Departamento de Matemática. III. Título.

CDD: 510 


\section{Agradecimentos}

À minha esposa, Kelly, que sempre me acompanhou em meus sonhos.

À minha recém-nascida filha Júlia, que nasceu para mudar meu mundo.

Aos meus pais, Anna e Gabriel, por todas as oportunidades dadas para que eu atingisse meu ápice.

À minha orientadora Renata Martins da Rosa, pela paciência, apoio e orientação. Não saberia começar este trabalho sem sua ajuda.

O presente trabalho foi realizado com apoio da Coordenação de Aperfeiçoamento de Pessoal de Nível Superior - Brasil (CAPES) - Código de Financiamento 001 


\section{Resumo}

Rosas Marinho, Diogo Vinícius; Rosa, Renata Martins da (orientadora). Algumas aplicações práticas de sistemas lineares e matrizes. Rio de Janeiro, 2020. 46 p. Dissertação de Mestrado - Departamento de Matemática, Pontifícia Universidade Católica do Rio de Janeiro.

Este trabalho faz uma introdução básica aos temas Cadeias de Markov e Matriz de Leontief visando mostrar aplicações práticas de sistemas lineares e matrizes com foco na aplicação no Ensino Médio brasileiro. Para tal, revisou-se as bases teóricas necessárias para o aluno ser capaz de entender e resolver problemas com estes temas. Em complemento, apresenta-se uma proposta de introdução à álgebra linear com geometria analítica, assim como a forma de cobrança da álgebra linear em concursos militares no Brasil. Com o uso de vídeos e ferramentas online, criando caminhos mais amistosos em assunto tão teórico, demonstra-se como o Youtube pode ser uma ferramenta poderosa na visualização de problemas abstratos envolvendo a álgebra linear.

\section{Palavras-chave}

Cadeias de Markov; Matriz de Leontief; Sistemas Lineares; Matrizes; Probabilidade; Álgebra linear; Youtube; Concursos militares 


\section{Abstract}

Rosas Marinho, Diogo Vinícius; Rosa, Renata Martins da (Advisor). Some practical applications of linear systems and matrices. Rio de Janeiro, 2020. 46 p. Dissertação de Mestrado - Departamento de Matemática, Pontifícia Universidade Católica do Rio de Janeiro.

This work makes a basic introduction to the themes Markov Chains and Leontief Matrix aiming to show practical applications of linear systems and matrices with a focus on its application in Brazilian High School. To achieve this goal, the theoretical bases necessary for the student to be able to understand and solve problems with these themes has been revised. In addition, we present a proposal to introduce linear algebra with analytical geometry, as well as the way of taking linear algebra in military tests in Brazil. With the use of videos and online tools and creating friendlier paths on such a theoretical theme, it is demonstrated how Youtube can be a powerful tool in visualizing abstract problems involving linear algebra.

\section{Keywords}

Markov Chain; Leontief Matrix; Linear systems; Matrices; Probability; Linear algebra; Youtube; Military exams 


\section{Sumário}

1. Introdução

2. Fundamentação teórica 13

2.1. Definições básicas de matrizes e suas operações 13

2.1.1 Exemplos práticos do uso de multiplicação de matrizes 14

2.2. Definições básicas de probabilidade 15

2.2.1. Experimento aleatório 16

2.2.2. Espaço amostral 16

$\begin{array}{ll}\text { 2.2.3. Evento } & 17\end{array}$

2.2.4. Combinação de eventos 17

2.2.4.1. União de dois eventos 18

$\begin{array}{ll}\text { 2.2.4.2. Intersecção de dois eventos } & 18\end{array}$

$\begin{array}{ll}\text { 2.2.4.3. Eventos complementares } & 18\end{array}$

2.2.4.4. União e intersecção de eventos formulados matematicamente 18

2.3. Definições básicas de Cadeias de Markov 19

2.3.1. Sistemas dinâmicos discretos de $1^{1 \stackrel{a}{ }}$ ordem 19

2.3.2. Processos estocásticos 20

2.3.3. Processo markoviano ou de Markov 20

2.3.4. Cadeias de Markov 21

2.3.4.1. Diagrama de transição 21

2.3.4.2. Exemplo de aplicação de cadeias de Markov 22

3. Aplicações no cotidiano das cadeias de Markov 27

3.1. Aplicação em estudo de preferências de população 27

3.2. Aplicação na demografia 29

3.2. Aplicação nas epidemias 30

4. Introdução à Matriz de Leontief 32 
5. Considerações gerais sobre o ensino da Álgebra Linear no ensino médio

6. O Youtube como ferramenta para aprendizagem 37

6.1. Os vídeos educacionais no Ensino da Álgebra Linear 37

6.2. Uso da ferramenta H5P nos vídeos educacionais 38

6.2.1. Atividade utilizando a ferramenta H5P 38

7. Considerações finais 41

8. Referências Bibliográficas 42

Apêndice A - Resolução de exercícios de concursos exibidos no capítulo 4 


\section{Lista de figuras}

Figura 1 - Exemplo de diagrama de transição 22

Figura 2 - Exemplo de cadeia de Markov em concurso 23

Figura 3 - Diagrama de transição 27

Figura 4 - Diagrama aplicação em epidemia 31

Figura 5 - Questão Escola Naval 34

Figura 6 - Questão Instituto Militar de Engenharia 35

Figura 7 - Print da tela da atividade criada em ambiente virtual $\quad 39$

Figura 8 - Print da tela da atividade criada em ambiente virtual 39

Figura 9 - Print da tela da atividade criada em ambiente virtual 39

Figura 10 - Print da tela da atividade criada em ambiente virtual $\quad 40$

Figura 11 - Print da tela da atividade criada em ambiente virtual $\quad 40$

Figura 12 - Esquema vetores mesma direção $\quad 45$

Figura 13 - Esquema cálculo área paralelogramo com dois vetores 46 
"Preste atenção não em quem diz, mas no que de bom se diga e guarde na memória. Se a meta principal de um capitão fosse preservar seu barco, ele o conservaria no porto para sempre. Três coisas são necessárias para a salvação do homem: Saber o que deve crer, o que deve querer, o que deve fazer!" 
São Tomás de Aquino

\section{1}

\section{Introdução}

Desde 1998 tenho contato direto com um tipo diferente de estudo: o estudo preparatório para concursos militares. Em 2003, após ingressar no Instituto Militar de Engenharia, decidi colocar em prática os aprendizados que absorvi com alunos particulares e em cursos preparatórios.

O diferencial que percebi é que temos que usar dinâmicas diferentes para alunos ou turmas diferentes. É dever do professor, usando minha vivência, procurar uma forma da sua classe absorver o máximo de informações durante suas aulas. $\mathrm{O}$ crescimento intelectual do aluno virá com essa aula em conjunto com o esforço individual, por exemplo, executando tarefas bem dimensionadas.

As aulas que proferi, tanto de matemática, física ou química, durante quase 16 anos, nunca foram organizadas em planos de aula estanques ou catalogadas para futuras aulas do mesmo tema. Sempre preparei as exposições com o devido estudo do tema e levantamento de questões- chave para melhor fixação do conteúdo. As aulas sempre transcorreram utilizando as dúvidas dos alunos como fio condutor. Com isso e com a postura adequada em sala de aula, tanto do professor quando dos alunos, quase sempre obtive boas respostas educacionais.

O objetivo deste trabalho é mostrar como dois temas do ensino médio, Sistemas Lineares e Matrizes, podem ser melhores absorvidos pelos alunos se expostos com exemplos práticos, sem perder o rigor matemático necessário. As ferramentas que nos são oferecidas nessa era devem ser amplamente utilizadas dentro das possibilidades de cada instituição de ensino. Quando não for possível o uso de vídeos em sala de aula, estimulemos nossos alunos a usar os celulares para ver tais vídeos.

Para atingir este objetivo irei mencionar a base teórica de cada tema além em dois temas que não são vistos em turmas do ensino médio: Cadeias de Markov e Matriz de Leontief. O motivo do uso destes temas é demonstrar que Sistemas Lineares e matrizes possuem usos complexos e práticos, respondendo assim a uma grande pergunta dos alunos: “onde, no cotidiano, usarei esses conhecimentos?”. Além disso irei expor como este tema é cobrado em concursos militares brasileiros. 
São alunos que precisam se preparar de forma mais completa do que a maioria dos estudantes que se preparam para vestibulares do "meio civil". As matérias cobradas nos concursos militares avançam em diversos pontos em itens apenas abordados nos primeiros semestres de algumas faculdades. Um aluno que se prepara para concursos desse tipo passariam de forma menos turbulenta pelas matérias do chamado "ciclo básico" de diversas universidades.

No final deste trabalho mostrarei links para vídeos no Youtube que mostram bases teóricas da álgebra linear de forma visual estimulando, assim espero, uma percepção mais amigável dos alunos e até mesmo professores em relação a esse tema muito temido nas salas de aula. 


\section{Fundamentação teórica}

Durante este capítulo será exposta de forma concisa os conceitos e bases matemáticas necessários para o entendimento de Sistemas lineares, Matrizes e, consequentemente, Cadeias de Markov.

As bases matemáticas aqui utilizadas são as mesma utilizadas nos currículos regulares do ensino médio brasileiro.

\section{1.}

\section{Definições básicas de matrizes e suas operações}

Antes de apresentarmos exemplos práticos de uso de matrizes e multiplicação de matriz, vamos recordar algumas definições. Não colocaremos aqui todos os conceitos e resultados que tipicamente aparece em um texto sobre matrizes, apresentando apenas o que explicitamente for utilizado neste trabalho.

De acordo com Anton (2001), uma matriz é um agrupamento retangular de números. Dizemos que os números nesse agrupamento são as entradas da matriz.

Seja $A$ uma matriz com $m$ linhas (fileiras horizontais) e $n$ colunas (fileiras verticais). Neste caso dizemos que $A$ é $m$ por $n$ e denotamos o tamanho de $A$ por $m$ x $n$. Denotando $a_{i j}$ a entrada de matriz $A$ que ocorre na sua linha $i$ e coluna $j$, podemos escrever $A=\left[a_{i j}\right]$.

Dependendo da disposição das suas entradas, a matriz pode receber denominações especiais, como matriz linha (aquela que possui uma única linha), matriz coluna (a que possui uma única coluna), matriz quadrada (possui o mesmo número de linhas e colunas), matriz nula (possui todas as entradas iguais a zero), entre outras.

Duas matrizes $A=\left[a_{i j}\right]$ e $B=\left[b_{i j}\right]$ são ditas iguais se tiverem o mesmo tamanho e se $a_{i j}=b_{i j}$ para todo $i$ e $j$.

O produto de um número real $k$ por uma $A=\left[a_{i j}\right]$ é a matriz obtida multiplicando-se cada entrada $A$ de por $k$, ou seja, $k A=\left[k a_{i j}\right]$. 
Se $A=\left[a_{i j}\right]$ e $B=\left[b_{i j}\right]$ são matrizes de mesmo tamanho, então a soma de $A+B$ é matriz obtida adicionando-se as entradas correspondentes de $A$ e $B$, ou seja, $A+B=\left[a_{i j}+b_{i j}\right]$.

Se $A=\left[a_{i j}\right]$ é uma matriz $m \times n$ e $B=\left[b_{i j}\right]$ é uma matriz $n \times p$, então o produto $A B$ é a matriz $m \times p$, digamos $C=\left[c_{i j}\right]$, com entradas $c_{i j}=a_{i 1} b_{1 j}+$ $a_{i 2} b_{2 j}+\cdots+a_{i n} b_{n j}$.

Observamos que, para multiplicar uma matriz $A$ por uma matriz $B$ e formar o produto $A B$, é necessário que o número de colunas de $A$ seja igual ao número de colunas de $B$.

A matriz identidade de tamanho $n \times n$ é a matriz quadrada $I_{n}=\left[a_{i j}\right]$, onde $a_{i j}=1$ sempre que $i=j$ e $a_{i j}=0$, caso contrário.

Observamos que, se matriz $A$ é uma matriz com $n$ linhas, então $I_{n} A=A$. Se matriz $B$ é uma matriz com $n$ colunas, então $B I_{n}=B$.

Uma matriz quadrada $A$ de tamanho $n \times n$ é dita invertível se existe uma matriz $B$ de mesmo tamanho tal que $A B=B A=I_{n}$. Neste caso $B$ é dita uma inversa de $A$.

É simples ver que a matriz inversa de $A$, quando existe, é única. Então podemos dizer que $B$ é a inversa de $A$ e denotar $B$ por $A^{-1}$.

\subsection{1.}

\section{Exemplos práticos do uso de multiplicação de matrizes}

Neste primeiro exemplo, consideramos em comerciante que vende garrafas de refrigerantes por $\mathrm{R} \$ 5,00$ e garrafas de água por $\mathrm{R} \$ 4,00$. Na tabela abaixo tem a quantidade de cada produto que foi vendida de segunda-feira até sexta-feira de uma determinada semana.

\begin{tabular}{|l|c|c|}
\hline & refrigerante & Água \\
\hline segunda-feira & 150 & 120 \\
\hline terça-feira & 100 & 70 \\
\hline quarta-feira & 130 & 78 \\
\hline quinta-feira & 220 & 160 \\
\hline sexta-feira & 250 & 200 \\
\hline
\end{tabular}


A multiplicação da matriz com a primeira linha da tabela pela matriz com os valores de uma garrafa de refrigerante e uma garrafa de água como abaixo nos dá o valor total da venda de segunda-feira:

$$
\left(\begin{array}{ll}
150 & 120
\end{array}\right)\left(\begin{array}{l}
5 \\
4
\end{array}\right)=150 \times 5+120 \times 4=1230
$$

Temos então que o total da venda segunda-feira foi $\mathrm{R} \$ 1230,00$. O mesmo processo funciona para os outros dias da semana.

O exemplo simples acima ilustra a necessidade de termos o número de colunas da primeira matriz igual ao número de linhas da segunda matriz.

O segundo exemplo tem a mesma ideia que o primeiro, mas pode chamar mais atenção dos alunos. Agora vamos usar mais notação formal de matrizes.

Consideremos a seguinte situação: Em um curso com cem alunos matriculados, o grau final de cada aluno depende das notas obtidos três provas sendo a primeira com peso 2, a segunda com peso 3 e a última com peso 5 . As notas dos alunos do curso podem ser organizadas em uma matriz onde cada linha contém os valores obtidos por um aluno nas três provas. Assim, construímos uma matriz 100 x 3 , digamos $A=\left[a_{i j}\right]$. Dessa forma, as notas do primeiro aluno da lista são $a_{11}, a_{12}$ e $a_{13}$, as notas do segundo são $a_{21}, a_{22}$ e $a_{23}$, e assim por diante.

Multiplicando a matriz $A$ pela matriz $3 \times 1$ dos pesos das provas, digamos $B=\left[b_{i j}\right]$, onde $b_{11}=0.2, b_{21}=0.3$ e $b_{31}=0.5$, obtemos a matriz $A B, 100 \times 1$, com os graus finais dos alunos no curso.

$$
\left(\begin{array}{ccc}
a_{11} & a_{12} & a_{13} \\
\vdots & \ddots & \vdots \\
a_{1001} & a_{1002} & a_{1003}
\end{array}\right) \cdot\left(\begin{array}{l}
\mathbf{0 . 2} \\
\mathbf{0 . 3} \\
\mathbf{0 . 5}
\end{array}\right)=\left(\begin{array}{c}
\text { grau do aluno } 1 \\
\text { grau do aluno } 2 \\
\vdots \\
\text { grau do aluno 100 }
\end{array}\right)
$$

\section{2.}

\section{Definições básicas de probabilidade}

A probabilidade é uma área da matemática que estuda as chances de obtenção de cada resultado de um experimento aleatório. 
A probabilidade matemática é representada por valores contidos no intervalo $[0,1]$.

Um evento, em um espaço amostral finito, tem probabilidade 0 de ocorrer quando é impossível e probabilidade 1 se for evento certo de ocorrer

Formulando matematicamente, temos:

$$
P(E)=\frac{n(E)}{n(S)}
$$

Onde:

$P(E)=$ probabilidade da ocorrência de um evento $E$

$n(E)=$ número total da ocorrência do evento $E$

$n(S)=$ número de ocorrência do espaço amostral finito $S$

\subsection{1.}

\section{Experimento aleatório}

Um experimento é dito aleatório quando não nas é possível determinar ou prever o resultado deste.

Um dos exemplos mais comuns de experimento aleatório é o lançamento de um dado. Se o dado não estiver viciado (com lados de tamanhos diferentes, por exemplo), a probabilidade de sair qualquer face é igual.

Outro exemplo que sempre aparece em questões de vestibulares é de uma sacola cheia de bolas azuis e amarela idênticas em forma e peso. Escolhendo uma das bolas ao acaso, às cegas, não há como saber se sairá uma bola azul ou amarela, gerando assim, um experimento aleatório.

\subsection{2.}

\section{Espaço amostral}

O espaço amostral é o conjunto de todos os resultados possíveis em um experimento aleatório. No exemplo anterior do lançamento de um dado, o espaço amostral S é representado por todos os valores do dado, isto é: $(S)=\{1,2,3,4,5,6\}$. 
Todos os resultados de um experimento aleatório estão contidos no espaço amostral, então, apesar de não ser possível prever o resultado, sabemos que os resultados de um lançamento de um dado só podem ser 1,2,3,4,5 ou 6 .

\subsection{3.}

\section{Evento}

O evento E é um subconjunto do espaço amostral S, ou seja, E está contido em S. Por exemplo podemos determinar que o evento de números pares ao lançar um dado seria $\mathrm{E}=\{2,4,6\}$.

Tipos de eventos:

- Evento certo: um evento certo é aquele em que $\mathrm{E}=\mathrm{S}$, ou seja, há absoluta certeza que este evento ocorrerá tal como, após o lançamento de um dados os números serem menores do que 7 , ou que este número seja natural.

- Evento Impossível: um evento impossível é aquele que não pertence ao espaço amostral. Ao lançar um dado padrão, não há chance de sair o número 8 , pois o dado não possui nenhuma face com o número 8 .

A probabilidade de ocorrência de um número par e de um número ímpar no lançamento de um dado são eventos complementares, pois os subconjuntos dos números pares e dos ímpares são disjuntos, ou seja, sem intersecção. Logo o somatório das ocorrências desses dois eventos é representado pelas 6 possibilidades: $\mathrm{E}=\{1,2,3,4,5,6\}$.

\subsection{4.}

\section{Combinação de eventos}

Se usarmos certas operações entre eventos (também chamados de conjuntos), poderemos combinar os eventos gerando novos eventos. 


\subsubsection{1.}

\section{União de dois eventos}

Sejam A e B dois eventos; então C = A U B também será um evento que ocorrerá se, e somente se, A ou B (ou ambos) ocorrem. Dizemos que C é a união entre os eventos A e B.

\subsubsection{2.}

\section{Intersecção de dois eventos}

Sejam A e B dois eventos; então $\mathrm{C}=\mathrm{A} \cap \mathrm{B}$ também será um evento que ocorrerá se, e somente se, A e B ocorrerem simultaneamente. Dizemos que C é a intersecção entre os eventos A e B.

Em particular, se $\mathrm{C}=\varnothing$ dizemos que os eventos A e B são mutuamente exclusivos.

\subsubsection{3.}

\section{Eventos complementares}

Eventos complementares são aqueles em que a intersecção entre eles é igual ao conjunto vazio e a união é representada por todo o espaço amostral.

\subsubsection{4.}

\section{União e intersecção de eventos formulados matematicamente}

A quantidade de elementos da união de dois conjuntos A e B tem como fórmula matemática:

$$
n(A U B)=n(A)+n(B)-n(A \cap B)
$$

Onde, $n(A)=$ número de elementos do conjunto $A$,

$n(B)=$ número de elementos do conjunto $B$ e

$n(A \cap B)=$ número de elementos pertencentes tanto ao conjunto $A$ quanto ao conjunto $B$. 
Dividindo-se a equação I por $n(S)$, que representa o número de elementos do espaço amostral S, temos

$$
\frac{n(A U B)}{n(S)}=\frac{n(A)}{n(S)}+\frac{n(B)}{n(S)}-\frac{n(A \cap B)}{n(S)}
$$

Pela definição básica de probabilidade, exposta anteriormente, teremos:

$$
\begin{aligned}
\frac{n(A U B)}{n(S)} & =P(A U B) \\
\frac{n(A)}{n(S)} & =P(A) \\
\frac{n(B)}{n(S)} & =P(B) \\
\frac{n(A \cap B)}{n(S)} & =P(A \cap B)
\end{aligned}
$$

Logo, reescrevendo a equação I teremos:

$$
P(A U B)=P(A)+P(B)-P(A \cap B),
$$

sendo que $P(A \cap B)$ representa a probabilidade dos eventos $\mathrm{A}$ e $\mathrm{B}$ ocorrerem simultaneamente.

\section{3.}

Definições básicas de Cadeias de Markov

\subsection{1.}

\section{Sistemas dinâmicos discretos de $1^{\text {a }}$ ordem}

Um sistema dinâmico discreto de $1^{\mathrm{a}}$ ordem é um sistema que evolui no tempo, sendo formado por um conjunto finito de variáveis com valores diferentes a cada momento. Estes valores são denominados: estados das variáveis naquele instante. Já o vetor formado por estes estados é denominado o estado do sistema dinâmico também naquele instante. 
Nas Cadeias de Markov os estados das variáveis não são conhecidos com absoluta certeza, mas podem ser dados como probabilidades, gerando sistemas dinâmicos chamados de processos estocásticos.

\subsection{2.}

\section{Processos estocásticos}

Em um processo estocástico com n possíveis estados, o vetor de estados em cada instante t tem o formato $x(t)=\left[\begin{array}{c}x_{1}(t) \\ x_{2}(t) \\ \vdots \\ x_{n}(t)\end{array}\right]$, onde $x_{j}(t)$ representa a probabilidade de que o sistema esteja no estado $\mathrm{j}$

O somatório de $x_{j}(t)$ para todos os $\mathrm{n}$ do vetor deve ser igual a 1 já que abrangem todas as $\mathrm{j}$ possibilidades. Estes vetores, com entradas não negativas e de soma 1, são chamados vetores probabilidade.

Uma matriz quadrada é dita estocástica se cada um de seus vetores coluna for um vetor probabilidade. Os estados sucessivos de um processo estocástico são formulados com matrizes estocásticas.

Existem vários tipos de processos estocásticos, mas neste trabalho focaremos no processo dito Markoviano.

\subsection{3.}

\section{Processo Markoviano ou de Markov}

Um processo de Markov assim chamado em homenagem ao matemático russo A. A. Markov, que criou esse processo para analisar poesias, é um processo estocástico em que a probabilidade atual depende apenas do estado imediatamente anterior, ou seja, para os processos de Markov o estado imediato é suficiente para definir os próximos estados. Os principais elementos de um processo de Markov são dois:

- A probabilidade $x_{n}(t)$ de ocorrer o estado n no t-ésimo período de tempo;

- As probabilidades de transição $\mathrm{m}_{\mathrm{ij}}$, que representam as probabilidades de o processo estar no estado i no tempo $(\mathrm{t}+1)$ dado que está no estado $\mathrm{j}$ no tempo t. Estas probabilidades de transição são normalmente agrupadas 
numa matriz, que denominamos matriz de transição, matriz estocástica ou ainda matriz de Markov.

\subsection{4.}

\section{Cadeias de Markov}

Podemos dizer que processos definidos como as Cadeias de Markov têm a propriedade markoviana ou um processo sem memória, isto é, se o futuro da evolução do processo depende apenas do momento em que ela está e não do que aconteceu anteriormente. Essa perda de memória é a base da caracterização das cadeias de Markov.

Muitos fenômenos que ocorrem na natureza e na sociedade podem ser estudados, pelo menos em uma primeira aproximação, como se os fenômenos passassem a partir de um estado inicial, por uma sequência de estados, onde a transição de um estado para o seguinte, ocorre segundo uma certa probabilidade.

No caso em que esta probabilidade de transição depende apenas do estado em que o fenômeno se encontra e do estado a seguir, o processo é denominado de Processo de Markov e uma sequência de estados envolvida nesse processo é denominada de Cadeia de Markov.

As Cadeias de Markov envolvem a matriz de transição, definida anteriormente, cujos elementos são as probabilidades de transição de um estado para outro. Para resolver um problema usando as Cadeias de Markov o diagrama de transição, além de nos ajudar a entender o problema, facilita a obtenção da matriz de transição que será usada para os cálculos efetivos.

Os eventos ou estados da matriz de transição devem ser complementares garantindo assim a soma ser igual a 1 ou $100 \%$.

\subsubsection{1.}

\section{Diagramas de transição}

O diagrama de transição é uma representação gráfica de uma Cadeia de Markov. Neste diagrama são visualizados os estados, representado por círculos, e as probabilidades de transição entre os estados. 


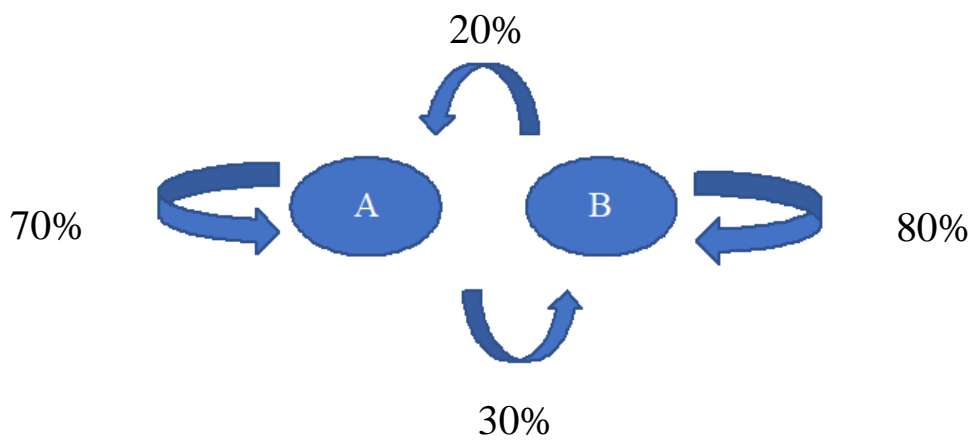

Figura 1 - Exemplo de diagrama de transição

Neste trabalho, estudaremos as Cadeias de Markov homogêneas, regulares e em um estado discreto.

Cadeias homogêneas são aquelas cujas probabilidades se mantêm no tempo, já o estado discreto condiz com etapas discretas, ou seja, o tempo não contínuo com adições discretas.

Dizemos que uma matriz de transição $P$ é regular se as entradas de qualquer potência $P^{k}$, são positivas. Uma cadeia de Markov com matriz regular é dita cadeia de Markov regular.

Com este conteúdo, podemos trabalhar, no Ensino Médio, assuntos como probabilidades, matrizes e sistemas lineares e, com isso, mostrar aos alunos que estes assuntos podem ser aplicados em outras áreas do conhecimento.

Teorema: Se $P$ for a matriz de transição de uma cadeia de Markov regular, então (a) Existe um único vetor probabilidade $q$ tal que $P . q=q$, ou seja, $(I-P) \cdot q=0$, onde $I$ é a matriz identidade.

(b) Dado qualquer vetor probabilidade inicial $x_{0}$, a sequência de vetores de estado: $x_{0}, P . x_{0}, \ldots, P^{k} . x_{0}, \ldots \quad$ converge ao vetor $q$.

A demonstração deste teorema, que foge ao escopo deste trabalho, pode ser encontrada em Kemeny \& Snell.

\subsubsection{2.}

\section{Exemplo de aplicação das cadeias de Markov}

- (CNJ 2013 - CESPE - Analista Judiciário). A população de um país é dividida em classes alta (A), média (M) e baixa (B). Um estudo estatístico mostra que, atualmente, $10 \%$ da população pertence à classe $\mathrm{A}, 40 \%$ à 
classe $\mathrm{M}$ e 50\% à classe B. Considera-se um modelo simplificado para as mudanças de classes, na forma de uma cadeia de Markov, em que as mudanças de uma geração para a próxima acontecem de acordo com a seguinte matriz de transição:

$$
M=\left(\begin{array}{ccc}
\text { A } & \text { M } & \text { B } \\
0,1 & 0,1 & 0 \\
0,6 & 0,2 \\
0 & 0,3 & 0,8
\end{array}\right)
$$

Figura 2 - Exemplo cadeia de markov em concurso

Assim, por exemplo, as probabilidades dos filhos de uma família da classe $\mathrm{M}$ pertencerem às classes $\mathrm{A}, \mathrm{M}$ ou $\mathrm{B}$ são iguais a 10\%,60\% e 30\%, respectivamente.

Com base nessa situação hipotética, julgue os itens subsequentes.

a) Se o modelo descrito valer por tempo indeterminado, então as proporções das classes A, M e B tenderão para as probabilidades estacionárias $2 / 7,2 / 7$ e $3 / 7$, respectivamente.

\section{- Resolução}

Sejam a, $\mathrm{m}$ e b as probabilidades estacionárias, ou seja, a probabilidade de o processo estar no estado j é constante e independente do estado inicial i, referentes as classes $\mathrm{A}, \mathrm{M}$ e $\mathrm{B}$.

As probabilidades dos filhos de uma família da classe A pertencerem às classes A, M ou B são iguais a 90\%, 10\% e 0\%, respectivamente.

$$
a=0,9 a+0,1 m
$$

As probabilidades dos filhos de uma família da classe $\mathrm{M}$ pertencerem às classes A, M ou B são iguais a 10\%, 60\% e 30\%, respectivamente.

$$
m=0,1 a+0,6 m+0,3 b
$$


As probabilidades dos filhos de uma família da classe B pertencerem às classes A, M ou B são iguais a $0 \%, 20 \%$ e $80 \%$, respectivamente.

$b=0,2 m+0,8 b$

Temos também que:

$a+m+b=1$

O nosso objetivo será resolver o sistema de equações abaixo:

$$
\begin{aligned}
& a=0,9 a+0,1 m(\mathrm{I}) \\
& m=0,1 a+0,6 m+0,3 b(\mathrm{II}) \\
& b=0,2 m+0,8 b(\mathrm{III}) \\
& a+m+b=1(\mathrm{IV})
\end{aligned}
$$

Manipulando as equações I, II ,III e IV:

$$
\begin{gathered}
a-m=0 \\
a-4 m+3 b=0 \\
m-b=0 \\
a+m+b=1
\end{gathered}
$$

Temos:

$$
\begin{aligned}
& a=1 / 3 \\
& m=1 / 3 \\
& b=1 / 3
\end{aligned}
$$

\section{Resposta: Falso}

b) Na próxima geração, $13 \%$ da população pertencerá à classe A, 35\% à classe $\mathrm{M}$ e $52 \%$ à classe $\mathrm{B}$. 


\section{- $\underline{\text { Resolução }}$}

Resolveremos a questão analisando agora as colunas da matriz de transição.

As colunas 1, 2 e 3 nos informam as chances de um indivíduo da próxima geração pertencer às classes A, M e B. Utilizaremos a informação do enunciado, que diz "atualmente, $10 \%$ da população pertence à classe A, $40 \%$ à classe $\mathrm{M}$ e $50 \%$ à classe B"

Classe A (linha 1):

$$
0,9 \cdot 0,1+0,1.0,4+0.0,5=0,09+0,04+0=0,13=13 \%
$$

Classe M (linha 2):

$$
0,1.0,1+0,6 \cdot 0,4+0,2 \cdot 0,5=0,01+0,24+0,1=0,35=35 \%
$$

Classe B (linha 3):

$0.0,1+0,3 \cdot 0,4+0,8 \cdot 0,5=0+0,12+0,4=0,52$

\section{Resposta: Certo}

c) Na hipótese de que o modelo tenha sido válido para a formação da geração atual, então as classes A, M e B na geração anterior eram formadas por $5 \%, 30 \%$ e $65 \%$ da população, respectivamente.

\section{- $\underline{\text { Resolucão }}$}

A resolução do item c é praticamente igual ao item b, a diferença é que agora nós queremos saber a geração anterior, e não a próxima.

Sejam x, y e z os valores referentes as classes A, M e B na geração anterior, e $0,1,0,4$ e 0,5 os valores referentes a geração atual.

Classe A (linha 1):

$$
0,9 x+0,1 y+0 z=0,1
$$


Classe M (linha 2):

$$
0,1 x+0,6 y+0,2 z=0,4
$$

Classe B (linha 3):

$$
0 x+0,3 y+0,8 z=0,5
$$

O nosso objetivo será verificar se $\{5 \%, 30 \%, 65 \%\}$ é a solução do sistema abaixo.

$$
\begin{aligned}
& 0,9 x+0,1 y=0,1 \\
& 0,1 x+0,6 y+0,2 z=0,4 \\
& 0,3 y+0,8 z=0,5
\end{aligned}
$$

Basta analisarmos a primeira equação para termos certeza que $\{5 \%, 30 \%$, $65 \%$ \} não é o conjunto solução.

Resposta: Errado 


\section{3}

\section{Aplicação no cotidiano das cadeias de Markov}

As cadeias de Markov são utilizadas em diversas áreas do nosso cotidiano. Desde processos na genética, estudos no transporte em massa, epidemias, estudo do clima e outras áreas onde probabilidade tem fator preponderante.

\section{1.}

\section{Aplicação em estudo de preferencias de população}

Suponha que em um determinado país existam dois bancos, os bancos A e B.

Os habitantes deste país são livres para usar qualquer um dos bancos, podendo trocar a qualquer momento.

Suponha que uma pessoa que usa o banco A no dia de hoje tem uma chance de $20 \%$ de estar usando o banco B daqui a um ano, enquanto uma pessoa que usa o banco B no dia de hoje migra para o banco A com chance de $70 \%$ após este mesmo período de 1 ano. Para efeito de simplificação, iremos supor que uma pessoa que use o banco A não usa o banco B e vice-versa, ou seja, $n(A \cap B)=\varnothing$

Para simplificar a análise, vamos supor que as probabilidades de troca introduzidas acima, ou probabilidades de transição, mantenham-se fixas ao longo dos anos.

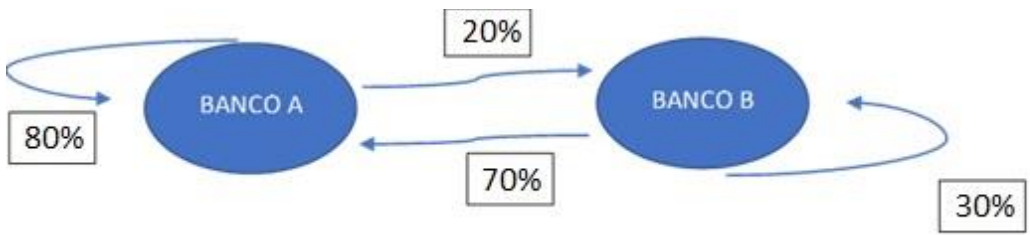

Figura 3 - Diagrama de transição

- Matriz de transição $\rightarrow \mathrm{P}=\left(\begin{array}{ll}0,80 & 0,70 \\ 0,20 & 0,30\end{array}\right)$ 
- Diagrama de probabilidades $\rightarrow$
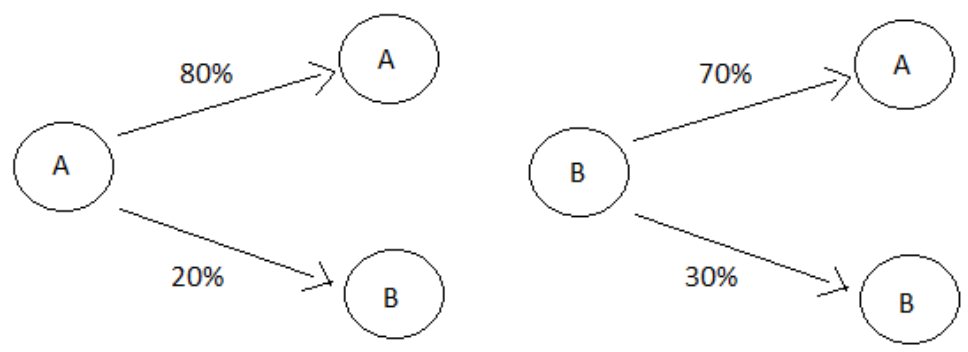

- Representando como matriz $\rightarrow$

\begin{tabular}{|c|c|c|}
\hline$A$ & $B$ & \\
\hline 0,8 & 0,7 & A \\
\hline 0,2 & 0,3 & B \\
\hline
\end{tabular}

- No início temos: Alguém está no banco A $\rightarrow\left(\begin{array}{l}1 \\ 0\end{array}\right)$

$$
\text { Alguém está no banco B } \rightarrow\left(\begin{array}{l}
0 \\
1
\end{array}\right)
$$

- Exemplo $1 \rightarrow$ Qual a probabilidade de alguém continuar usando o banco A após 2 anos?

- Usando diagrama de probabilidades

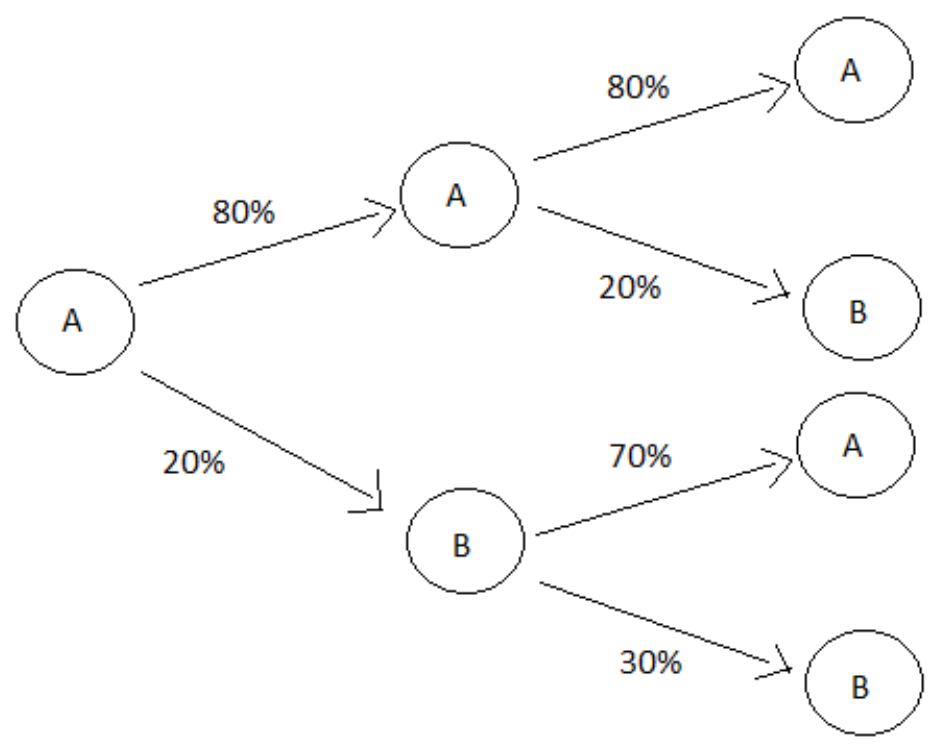

Temos então $\rightarrow 80 \% * 80 \%+20 \% * 70 \%=0,78$ ou $78 \%$ 
- Usando matrizes, temos $\rightarrow\left(\begin{array}{ll}0,80 & 0,70\end{array}\right) *\left(\begin{array}{l}0,80 \\ 0,20\end{array}\right)=0,78$

- Exemplo $2 \rightarrow$ Qual a probabilidade de alguém mudar para o banco B após 2 anos?

- Usando diagrama de probabilidades

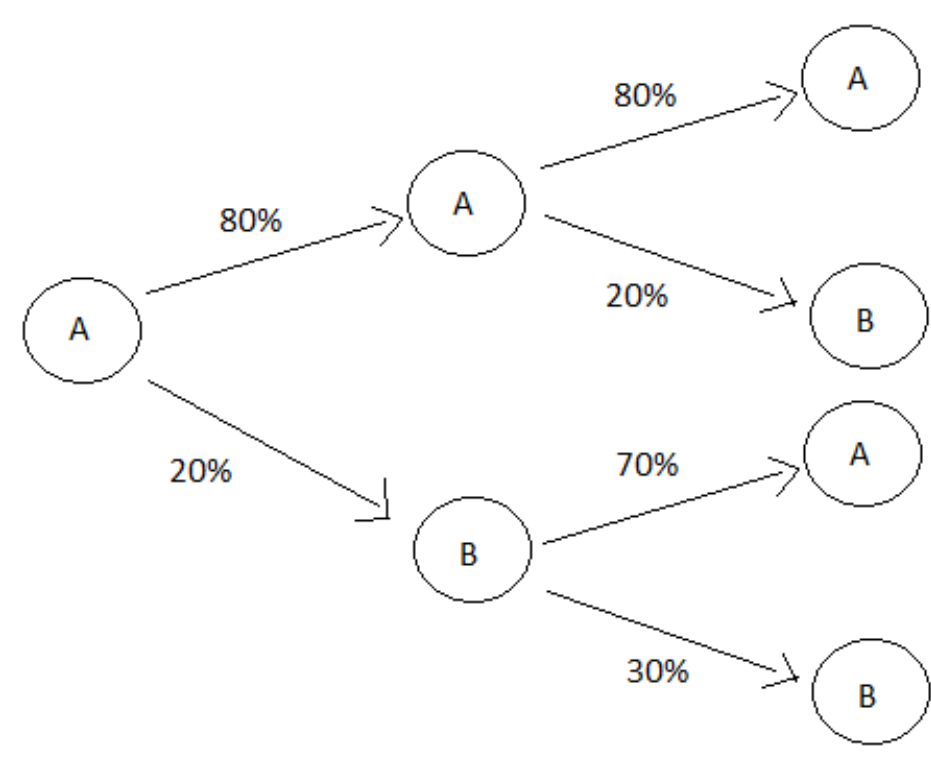

Temos então $\rightarrow 80 \% * 20 \%+20 \% * 30 \%=0,22$ ou $22 \%$

- Usando matrizes, temos $\rightarrow(0,20 \quad 0,30) *\left(\begin{array}{l}0,80 \\ 0,20\end{array}\right)=0,22$

OBS: Perceba que o resultado do exemplo 1 somado ao resultado do exemplo 2 dá 1 ou $100 \%$ já que os eventos dos dois exemplos são complementares

\section{2.}

\section{Aplicação na demografia}

Um objeto de estudo dos demógrafos é o movimento das populações, ou grupo de pessoas, de uma região para outra. Vamos considerar um modelo simples para variação da população de uma cidade e dos subúrbios vizinhos ao longo de determinado período de anos. Suponha que um estudo demográfico mostre que a cada ano, aproximadamente $5 \%$ da população da cidade se mude para o subúrbio 
(significa que $95 \%$ permanecem na cidade) enquanto $3 \%$ da população dos subúrbios se mudam para a cidade (isto é, 97\% permanecem no subúrbio). Sabendo que a população inicial na cidade é de 600000 habitantes e no subúrbio 400000 habitantes, analise os efeitos dessa migração ao longo de dois anos, verificando a quantidade de habitantes em cada lugar ao longo do tempo

- $\underline{\text { Resolução: }}$

$\mathrm{P}=\left(\begin{array}{ll}0,95 & 0,03 \\ 0,05 & 0,97\end{array}\right) \rightarrow$ matriz das probabilidades, onde coluna $1=$ CIDADE coluna 2 = SUBÚRBIO

- Após $1^{\circ}$ ano $\rightarrow\left(\begin{array}{ll}0,95 & 0,03 \\ 0,05 & 0,97\end{array}\right) \cdot\left(\begin{array}{l}600000 \\ 400000\end{array}\right)=\left(\begin{array}{l}582000 \\ 418000\end{array}\right)$

- Após $2^{\circ}$ ano $\rightarrow\left(\begin{array}{ll}0,95 & 0,03 \\ 0,05 & 0,97\end{array}\right) \cdot\left(\begin{array}{l}582000 \\ 418000\end{array}\right)=\left(\begin{array}{l}565440 \\ 434560\end{array}\right)$

Logo, após 2 anos, haverá 565.000 pessoas na cidade e 434.560 pessoas no subúrbio

\section{3.}

\section{Aplicação nas epidemias}

Uma vez que um processo de contágio é Markoviano é possível modelá-lo através de cadeias de Markov.

O modelo implementado baseia-se no SIR (Suscetível, Infectado, Recuperado ou Removido).

Supõe-se a modelagem da evolução de um surto infecioso numa enfermaria com três pacientes, colocados em camas adjacentes.

Considerando que o surto se inicia com a infeção do paciente do "meio", estando os dois outros pacientes suscetíveis de serem infetados com uma taxa de contágio que se mantém constante ao longo do surto. Para efeito de simplificação, considerase também que dois pacientes não adjacentes não se podem contagiar mutuamente. Após contágio, cada paciente torna-se infecioso durante dois dias. Terminado esse 
período o paciente passa ao estado recuperado, não podendo voltar a contrair a infecção.

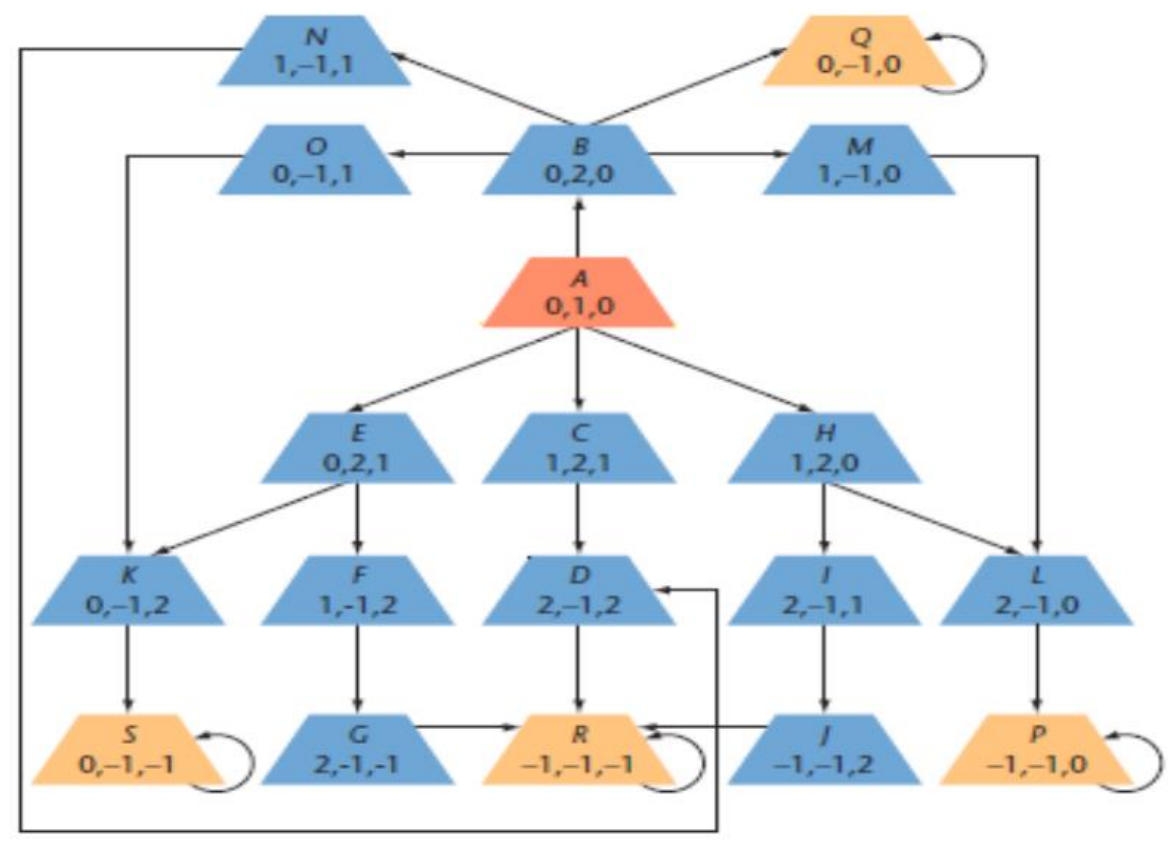

Figura 4 - Diagrama aplicação em epidemia

Fonte: FIDALGA, Nicole Helena Duarte. Aplicações das cadeias de Markov à modelação matemática de epidemias. 2016. Tese de Doutorado.

Os estados em que cada paciente se pode encontrar são descritos através do números $-1,0,1$ e 2, que correspondem respetivamente a: recuperado (R), suscetível (S), infetado (I) no primeiro dia e infetado no segundo dia. A Figura 3 representa o diagrama de transição de estados dos três pacientes. O estado inicial, representado pela letra $\mathrm{A}$ contém a tripla $(0,1,0)$ que indica que o paciente da esquerda é suscetível, o do meio está infecioso no primeiro dia e o da direita está igualmente suscetível. Este diagrama mostra que existem 19 estados possíveis, representados pelas letras compreendidas entre A e S.

Devido à complexidade deste exemplo, fugindo assim do escopo deste trabalho, não iremos desenvolver o raciocínio iniciado anteriormente. A intenção desta exposição é mostrar que há aplicação da Cadeia de Markov até mesmo nas epidemias/pandemias (tal como a atual COVID-19). 


\section{4}

\section{Introdução à Matriz de Leontief}

Neste capítulo veremos um exemplo do uso de sistema linear e matriz na economia.

Wassily Wassilyovitch Leontief foi um economista russo, naturalizado americano notável por pesquisas sobre como as mudanças em um único setor da economia afetam os demais. Recebeu o Prémio Nobel em economia de 1973 pelo desenvolvimento da matriz de insumo-produto (input-output), conhecida como a "matriz de Leontief", e a sua aplicação à economia.

Vamos começar primeiro com um exemplo simples que não necessita de Álgebra Linear.

- Uma usina que produz energia também consume parte desta produção. Se a usina precisa produzir mais para atender à demanda do mercado, irá precisar também consumir mais.

Suponhamos que uma certa usina precisa consumir 5\% do que produz e que o mercado precisa de uma quantidade de energia que equivale a $\mathrm{R} \$ 700.000,00$.

Como saber a quantidade de energia, em reais, que a usina precisa produzir para atender essa demanda e seu consumo interno?

Para a solução seja $\mathrm{X}$ o valor total em energia que a usina precisa produzir, então X é a soma de 700.000 com 5\% de X, ou seja, x satisfaz

$$
\begin{aligned}
X & =700.000+0,05 X \rightarrow X-0,05 X=700.000 \rightarrow(1-0,05) X= \\
700.000 & \rightarrow 0,95 X=700.000 \rightarrow X=736.842,10
\end{aligned}
$$

Agora iremos passar para o caso em que se estuda uma economia onde setores se influenciam mutuamente. Neste caso sejam, por exemplo, os setores A e B da economia de um certo país. O setor A produz a matéria prima $m_{a}$ e o setor B $m_{b}$. Para produzir sua matéria prima, o setor A consome 5\% de sua própria matéria prima e $85 \%$ do que é produzido pelo setor B. Já o setor B consome $70 \%$ do que é produzido pelo setor A e $10 \%$ do que ele próprio produz. O resto é distribuído no mercado interno deste país. Suporemos também que há uma demanda total de $D_{a}$ da materia prima produzida por A e $D_{b}$ pelo B. 
Usando raciocínio análogo ao do exemplo simplificado acima, temos a seguinte expressão matemática:

$$
\left[I-\left(\begin{array}{ll}
0,05 & 0,85 \\
0,70 & 0,10
\end{array}\right)\right] \cdot\left(\begin{array}{l}
m_{a} \\
m_{b}
\end{array}\right)=\left(\begin{array}{c}
D_{a} \\
D_{b}
\end{array}\right), \text { onde } I=\text { Matriz identidade }
$$

Como normalmente a demanda da população é definida, temos que calcular o vetor $\left(\begin{array}{c}m_{a} \\ m_{b}\end{array}\right)$ para saber o quanto cada setor deve produzir, temos que utilizar uma matriz inversa para fazer os cálculos conforme explicado abaixo:

$$
\begin{gathered}
{\left[I-\left(\begin{array}{ll}
0,05 & 0,85 \\
0,70 & 0,10
\end{array}\right)\right] \cdot\left(\begin{array}{l}
m_{a} \\
m_{b}
\end{array}\right)=\left(\begin{array}{l}
D_{a} \\
D_{b}
\end{array}\right) \rightarrow\left(\begin{array}{l}
m_{a} \\
m_{b}
\end{array}\right)=\left[I-\left(\begin{array}{ll}
0,05 & 0,85 \\
0,70 & 0,10
\end{array}\right)\right]^{-1} \cdot\left(\begin{array}{l}
D_{a} \\
D_{b}
\end{array}\right)} \\
\rightarrow\left(\begin{array}{l}
m_{a} \\
m_{b}
\end{array}\right)=\left[\left(\begin{array}{cc}
0,95 & -0,85 \\
-0,70 & 0,90
\end{array}\right)\right]^{-1} \cdot\left(\begin{array}{l}
D_{a} \\
D_{b}
\end{array}\right) \\
\left(\begin{array}{l}
m_{a} \\
m_{b}
\end{array}\right)=\left(\begin{array}{ll}
45 / 13 & 85 / 26 \\
35 / 13 & 95 / 13
\end{array}\right) \cdot\left(\begin{array}{l}
D_{a} \\
D_{b}
\end{array}\right)
\end{gathered}
$$

A matriz de Leontief consegue assim calcular, teoricamente, quanto cada setor deve produzir para abastecer a demanda total de um país. 


\section{5 \\ Considerações gerais sobre o ensino da Álgebra Linear no ensino médio}

A álgebra linear é um ramo da matemática pouco explorados no ensino médio. A falta de tempo é um dos fatores deste pouco uso em sala de aula assim como a diminuição da complexidade das questões envolvendo vetores, sistema lineares e matrizes em vestibulares tradicionais (ENEM incluso) desde o ano 2000. Certamente esse assunto faz falta para os alunos que seguem estudos na área técnica e científica, mas também para os demais já que mesmo na área de humanas é necessário minimamente o uso de matrizes para organizar informações em tabelas.

Além disso, em concursos militares, no nível de ensino médio, há cobrança de questões complexas em relação aos tópicos de álgebra linear. Nos editais costuma-se colocar esses tópicos simplesmente como vetores, sistemas lineares, matrizes e determinantes. Com certa experiência no ensino para este tipo de concurso, o autor percebeu que uma boa explanação da teoria, com muitas ramificações possíveis, não substitui uma exposição dinâmica e com foco no uso prático da álgebra linear. Para dar uma ideia do conteúdo cobrado comentamos duas questões de concurso.

- Escola Naval (2019)

\section{QUESTÃO 4}

Seja a matriz $M=\left[\begin{array}{lll}1 & 1 & 1 \\ 1 & 0 & 0 \\ 0 & 1 & 0\end{array}\right]$ onde $M^{n}=M \times M \times \ldots \times M$, com $n$ fatores, $x$ a soma dos elementos da $1^{\text {a }}$ coluna de $M^{12}$ e $y$ a soma dos elementos da $3^{a}$ coluna de $M^{12}$. Nesse caso, o valor de $x-y$ é:
(A) 504
(B) 927
(C) 778
(D) 1431
(E) 1705

Figura 5 - Questão Escola Naval 
Um aluno típico do ensino médio poderia desistir ao achar que teria que multiplicar a matriz $M$ doze vezes. Mas podemos ensino ao aluno a procurar padrões assim como na vida cotidiana. Mostrar um exemplo prático de uso de potência de matriz também pode ser útil para motivar e dar sentido para tais contas.

- Instituto Militar de Engenharia (2019)

Uma matriz A é semelhante a uma matriz B se e somente se existe uma matriz invertível $\mathrm{P}$ tal que $\mathrm{A}=\mathrm{PB} \mathrm{P} \mathrm{P}^{-1}$.

a) Se $\mathrm{A}$ e $\mathrm{B}$ forem semelhantes, mostre que $\operatorname{det}(\mathrm{A})=\operatorname{det}(\mathrm{B})$.

b) Dadas $C=\left(\begin{array}{ll}4 & 2 \\ 3 & 5\end{array}\right)$ e $\mathrm{D}=\left(\begin{array}{cc}8 & -2 \\ 3 & 1\end{array}\right)$, verifique se essas matrizes são semelhantes.

Figura 6 - Questão Instituto Militar de Engenharia

O aluno muito teórico iria pensar nas propriedades das matrizes diagonalizáveis, cuja teoria é cobrada em diversos concursos militares e poderia perder-se na solução. Esse tipo de pensamento é bem comum na experiência do autor tanto como aluno como professor dos cursos preparatórios. A tendência desses alunos é dificultar algumas questões ao invés de simplificá-las. Já aquele aluno treinado para buscar soluções mais práticas e perceber que, escrevendo $\mathrm{AP}=\mathrm{PB}$, pode resolver a questão de forma rápida.

O desenvolvimento dessas duas questões pode ser visto no Apêndice A.

Álgebra linear advém do estudo de sistemas de equações lineares utilizando alguns conceitos e estruturas fundamentais da matemática como vetores, espaços vetoriais, transformações lineares, sistemas de equações lineares e matrizes. No ensino médio seria possível introduzir álgebra linear no estudo de geometria analítica quando é necessário resolver sistemas lineares, por exemplo. O uso de vetores representado com coordenadas ou como matriz coluna também pode ser útil. Muitas vezes os alunos entendem que uma matriz é uma tabela de informações, mas nem sempre sabem para que serve as contas feitas com essas tabelas. Por exemplo, no ensino médio é ensinado o cálculo de determinante de uma matriz quadrada de duas linhas e duas colunas, mas nem sempre é dado algum significado ou uso para esse determinando. Se o aluno usa vetores com coordenadas, então poderia aprender que o determinante mencionado serve para determinar se dois 
vetores no plano têm a mesma direção e também para o cálculo da área do paralelogramo formado por dois vetores no plano. No Apêndice B, desenvolvemos esse exemplo.

Relacionar álgebra linear e geometria analítica é muito interessante e importante pelo apelo visual. Mesmo assim o aluno poderia se perguntar sobre o uso prático da própria geometria analítica. Exemplos práticos do uso de matrizes e sistemas lineares e aplicáveis ao cotidiano podem motivar e justificar o estudo de álgebra linear. 
O Youtube como ferramenta para aprendizagem

Os vídeos educacionais, lançados no youtube ou em outras plataformas de vídeos online, são ferramentas relegadas no ensino da matemática no Brasil.

Neste ano de 2020, com a pandemia mundial deflagrada desde o início do ano, as ferramentas educacionais estão sendo testadas de forma ampla. Percebe-se que ainda há muito espaço para melhora tanto da quantidade quanto da qualidade das aulas virtuais. Outro ponto totalmente relegado na realidade brasileira, o ensino doméstico, também pode ser otimizado com a enorme publicação de vídeos educacionais.

\section{1.}

\section{Os vídeos educacionais no Ensino da Álgebra Linear}

A dificuldade da maioria dos alunos, qual seja a visualização das operações feitas "no papel", pode ser mitigada com o uso constante desses tipos de vídeos educacionais.

No estudo da álgebra linear, por exemplo, existem diversos vídeos que ajudam na visualização das operações matemática que quase nada significam se só vistos como resolução de problemas em sala de aula.

Um canal referência, nessas visualizações matemáticas, é o 3blue1brown (https://www.youtube.com/channel/UCYO_jab_esuFRV4b17AJtAw).

Os vídeos possuem legendas em português feitas por voluntários e podem estimular tanto o estudo matemático quanto o desenvolvimento do inglês, principalmente o falado. Esse desenvolvimento seria um via de mão dupla ao apelar para o visual tanto na aprendizagem da matemática quanto na aplicação do inglês em algo fora da aula destinada ao ensino desta língua.

Outra forma de maximizar este aprendizado com vídeos em inglês seria não apresentar o áudio, explicando em sala de aula e deixando para o aluno, em casa, visualizar o vídeo já com legendas em português.

Com a devida autorização do dono deste canal, exponho aqui uma série de vídeos introdutórios à Álgebra Linear, cujas legendas foram feitas por voluntários 
e revisadas por mim.

https://www.youtube.com/watch?v=fNk_zzaMoSs\&list=PLZHQObOWTQDPD3

MizzM2xVFitgF8hE_ab.

Em um dos vídeos desta série (https://www.youtube.com/watch?v=fNk_zzaMoSs), em torno do minuto 8, temos, por exemplo, as definições de vetores de mesma direção conforme visto no capítulo 4.2.2.1.

\section{2.}

Uso da ferramenta H5P nos vídeos educacionais

O H5P é uma ferramenta gratuita que tem por função proporcionar interatividade com o estudante por meio de atividades em ambientes virtuais. Essa ferramenta também permite que se crie vídeos, textos, áudios os quais provocam uma ação dinâmica por parte do aluno.

Com a finalidade de obter uma reação por parte de quem assiste, pode-se incluir perguntas, enquete ou pesquisas que aparecem durante, por exemplo, videoaulas. Assim este aluno pode participar, selecionando a resposta, sem perder o que está sendo dito na videoaula.

\subsection{1.}

\section{Atividade utilizando a ferramenta H5P}

Utilizando-se este trabalho como referência, elaborei atividade utilizando o vídeo já posto acima (https://www.youtube.com/watch?v=fNk_zzaMoSs) em ambiente virtual com esta poderosa ferramenta. 


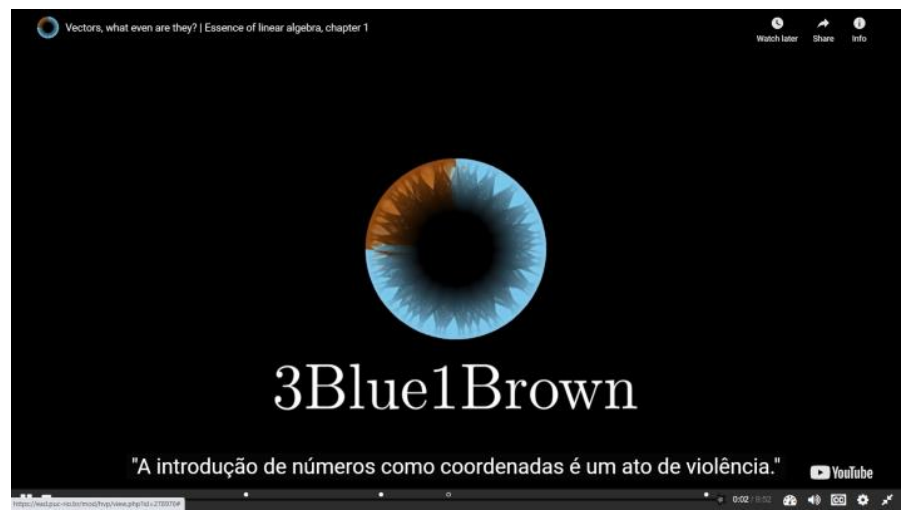

Figura 7 - Print da tela da atividade criada em ambiente virtual

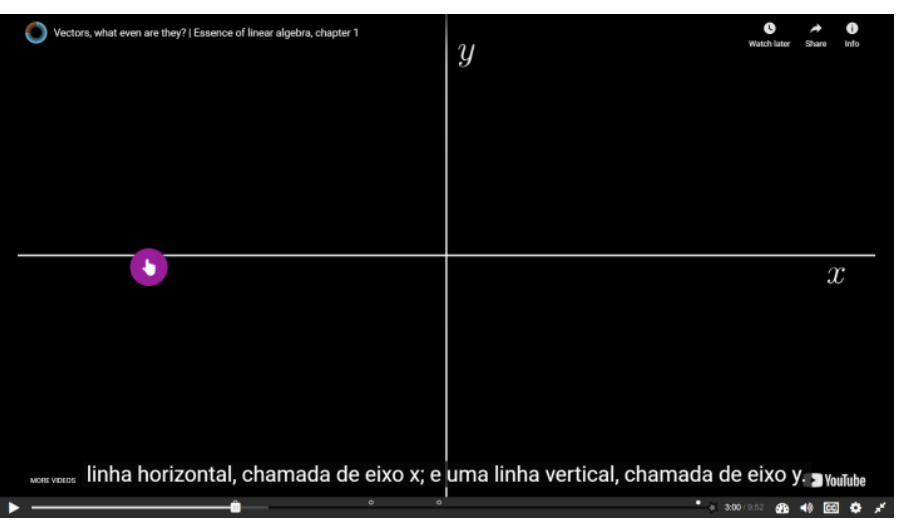

Figura 8 - Print da tela da atividade criada em ambiente virtual

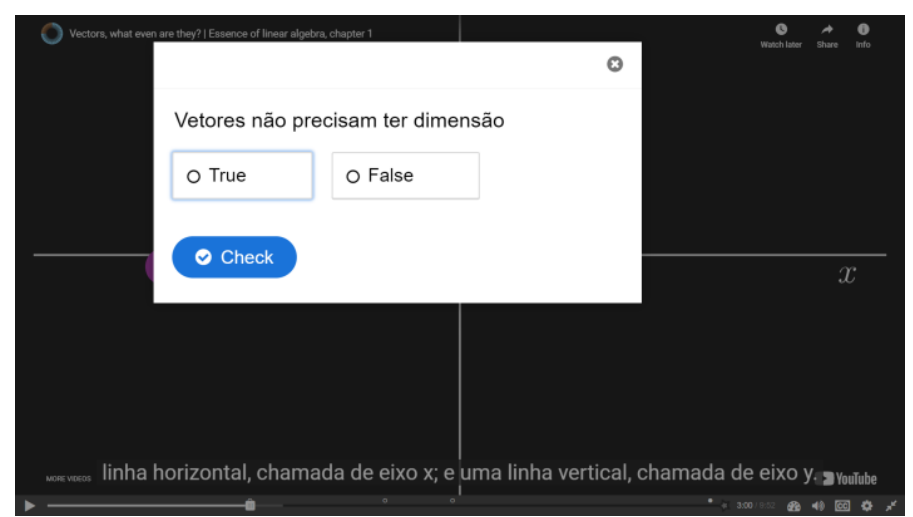

Figura 9 - Print da tela da atividade criada em ambiente virtual 


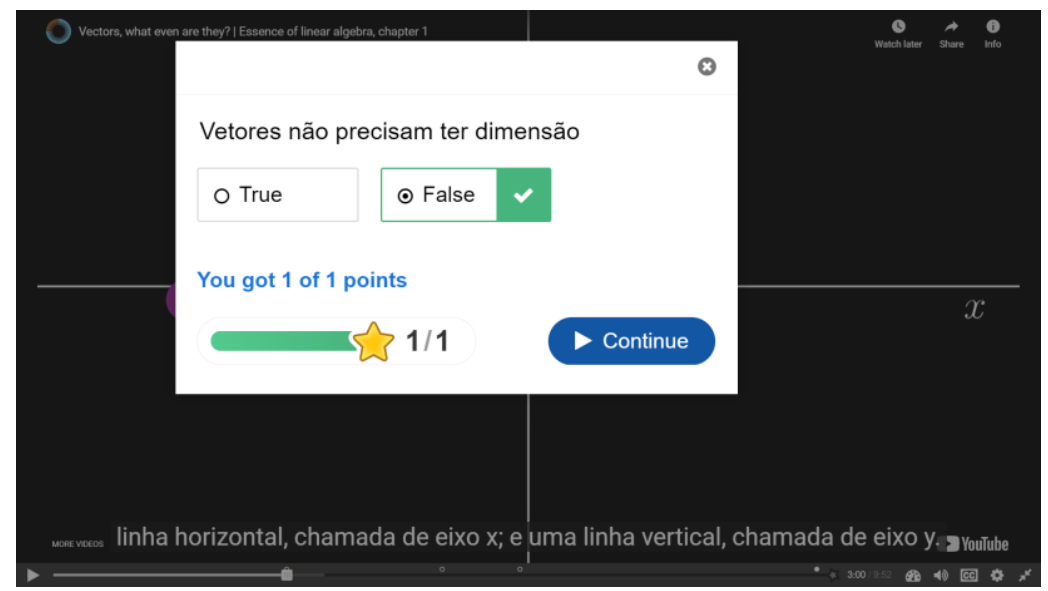

Figura 10 - Print da tela da atividade criada em ambiente virtual

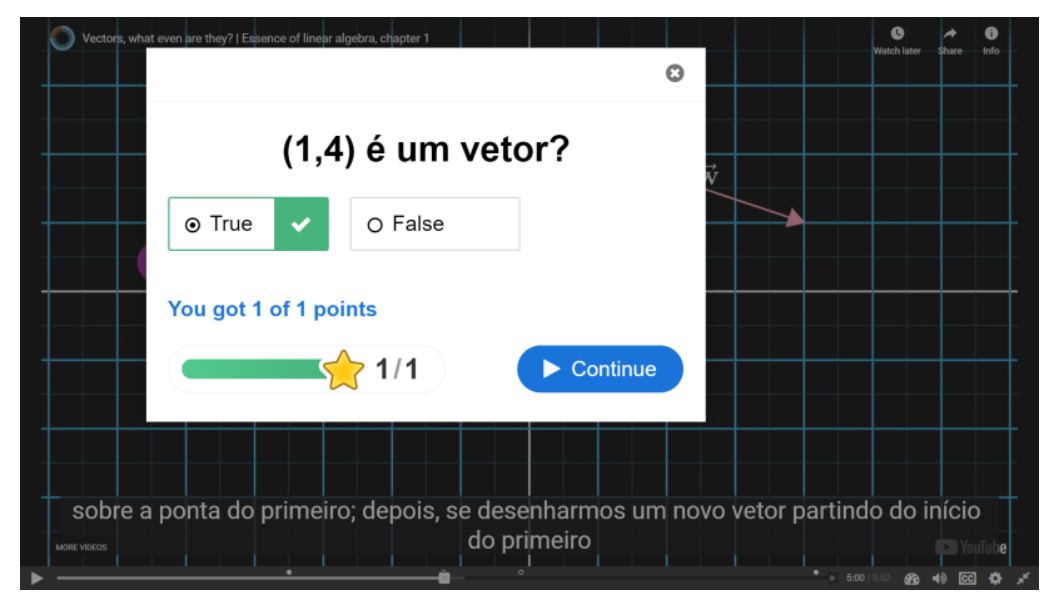

Figura 11 - Print da tela da atividade criada em ambiente virtual 


\section{Considerações finais}

O trabalho teve como objetivo demonstrar o quão importante é a apresentação de um tema demasiadamente teórico utilizando ferramentas modernas de vídeos , por exemplo no youtube, tornando assim mais "visual" e "contextualizado" o ensino de sistemas lineares e matrizes.

No tema álgebra linear, os melhores vídeos que encontrei à disposição foram feitos por estrangeiros, principalmente na língua inglesa. Seria interessante o trabalho de criar vídeos em português para melhor apresentar esses conteúdos aos estudantes brasileiros.

As ferramentas de edição de vídeos, tal como o H5P, apareceram para complementar de forma muito dinâmica essa exposição de videoaulas. As novas gerações precisam ser estimuladas a aproveitar ao máximo essas ferramentas modernas juntando o ensino "analógico" ao "digital" 


\section{8}

\section{Referências bibliográficas}

ANTON, H \& RORRES, C. Álgebra Linear com Aplicações. 8a. ed. Porto Alegre: Editora Bookman, 2001.

FIDALGA, Nicole Helena Duarte. Aplicações das cadeias de Markov à modelação matemática de epidemias. 2016. Tese de Doutorado.

KEMENY, J. G.; SNELL, J. L. Finite Markov Chains. Springer. N. York. 1976.

HAZZAN, Samuel e IEZZI, Gelson. Fundamentos de Matemática Elementar: Combinatória, Binômio e Probabilidade. Volume 5. São Paulo: Editora Atual, 2006.

LIMA, Elon. Álgebra linear. Coleção Matemática Universitária. 1995.

LIMA, Elon. Geometria Analítica e Álgebra Linear. 2a ed. Coleção Matemática Universitária. IMPA, 2008

https://pt.wikipedia.org/wiki/\%C3\%81lgebra linear (acessada no dia $14 / 07 / 2020$ as $13: 30)$ 


\section{Apêndice A - Resolução dos exercícios de concurso exibidos no capítulo 4}

- Exercício da Escola Naval (2019) mostrado na página 34

$\underline{\text { Resolução: }}$

$$
\begin{aligned}
& M=\left(\begin{array}{lll}
1 & 1 & 1 \\
1 & 0 & 0 \\
0 & 1 & 0
\end{array}\right) \\
& M^{2}=\left(\begin{array}{lll}
1 & 1 & 1 \\
1 & 0 & 0 \\
0 & 1 & 0
\end{array}\right) \cdot\left(\begin{array}{lll}
1 & 1 & 1 \\
1 & 0 & 0 \\
0 & 1 & 0
\end{array}\right)=\left(\begin{array}{lll}
2 & 2 & 1 \\
1 & 1 & 1 \\
1 & 0 & 0
\end{array}\right) \\
& M^{3}=M^{2} \cdot M=\left(\begin{array}{lll}
2 & 2 & 1 \\
1 & 1 & 1 \\
1 & 0 & 0
\end{array}\right) \cdot\left(\begin{array}{lll}
1 & 1 & 1 \\
1 & 0 & 0 \\
0 & 1 & 0
\end{array}\right)=\left(\begin{array}{lll}
4 & 3 & 2 \\
2 & 2 & 1 \\
1 & 1 & 1
\end{array}\right) \\
& M^{6}=M^{3} \cdot M^{3}=\left(\begin{array}{lll}
4 & 3 & 2 \\
2 & 2 & 1 \\
1 & 1 & 1
\end{array}\right) \cdot\left(\begin{array}{lll}
4 & 3 & 2 \\
2 & 2 & 1 \\
1 & 1 & 1
\end{array}\right)=\left(\begin{array}{ccc}
24 & 20 & 13 \\
13 & 11 & 7 \\
7 & 6 & 4
\end{array}\right) \\
& M^{12}=M^{6} \cdot M^{6}=\left(\begin{array}{ccc}
24 & 20 & 13 \\
13 & 11 & 7 \\
7 & 6 & 4
\end{array}\right) \cdot\left(\begin{array}{ccc}
24 & 20 & 13 \\
13 & 11 & 7 \\
7 & 6 & 4
\end{array}\right)=\left(\begin{array}{ccc}
927 & 778 & 504 \\
504 & 423 & 274 \\
274 & 230 & 149
\end{array}\right) \\
& x=927+504+274 \\
& y=504+274+149 \\
& x-y=927-149=778
\end{aligned}
$$

Observamos que só se pode fazer isso quando as potencias são iguais já que não existe propriedade comutativa na multiplicação de matrizes. Além disso, percebese que o termo $a_{13}=a_{21}$ e $a_{23}=a_{31}$, com isto facilitando ainda mais o cálculo repetitivo. 
- Instituto Militar de Engenharia (2019) mostrado na página 35

Resolução:

a) $A=P B P^{-1} \rightarrow \operatorname{det} A=\operatorname{det} \quad\left(P B P^{-1}\right) \rightarrow \quad \operatorname{det} A=$ $\operatorname{det} P . \operatorname{det} B . \operatorname{det} P^{-1}, \mathrm{como} \operatorname{det} \mathrm{P} . \operatorname{det} \mathrm{P}^{-1}=1 \rightarrow \operatorname{det} A=1 . \operatorname{det} B \rightarrow$ $\operatorname{det} A=\operatorname{det} B$

b) $C=\left(\begin{array}{ll}4 & 2 \\ 3 & 5\end{array}\right)$ e $D=\left(\begin{array}{rr}8 & -2 \\ 3 & 1\end{array}\right)$. Como $C$ e $D$ são semelhantes, temos $C P=$ $P D$, sendo $P$ uma matriz invertível, então:

$$
P=\left(\begin{array}{ll}
x & y \\
z & w
\end{array}\right) \rightarrow \mathrm{CP}=\left(\begin{array}{ll}
4 x+2 z & 4 y+2 w \\
3 x+5 z & 3 y+5 w
\end{array}\right) \text { e } P D=\left(\begin{array}{ll}
8 x+3 y & -2 x+y \\
8 z+3 w & -2 z+w
\end{array}\right)
$$

$$
\begin{aligned}
\mathrm{CP}=\mathrm{PD} \leftrightarrow 4 x+3 y-2 z & =0 \text { (I) } \\
2 x+3 y+2 w & =0 \text { (II) } \\
3 x-3 z-3 w & =0 \text { ou } w=x-z \text { (III) } \\
3 y+2 z+4 w & =0 \text { (IV) }
\end{aligned}
$$

Substituindo a equação III nas equações II e IV, temos:

$I I \rightarrow 2 x+3 y+2(x-z)=0 \rightarrow 4 x+3 y-2 z=0 \rightarrow$ igual à equação $\mathrm{I}$ $I V \rightarrow 3 y+2 z+4(x-z)=0 \rightarrow 4 x+3 y-2 z=0 \rightarrow$ igual à equação I

Logo as soluções advêm somente das equações I e III. Tomando $\mathrm{x}=\mathrm{z}=3$, temos $\mathrm{y}$

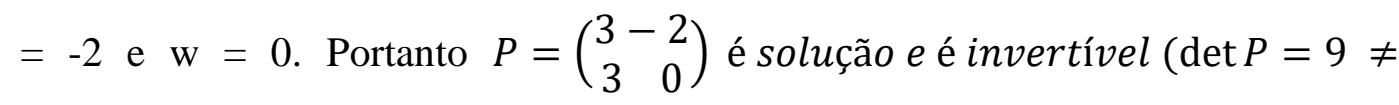
$0)$, concluindo que C e D são semelhantes. 


\section{Apêndice B - Vetores paralelos no plano e determinante}

Dizemos que dois vetores não nulos, $\vec{u}$ e $\vec{v}$, representados algebricamente, têm a mesma direção se e só eles são múltiplos.

Sejam $\vec{u}$ e $\vec{v}$ dois vetores não nulos no plano cartesiano, digamos $\vec{u}=(a, b)$ e $\vec{v}=(c, d)$, então $\vec{u}$ e $\vec{v}$ têm a mesma direção se e só se $\vec{u}=k \vec{v}$, com $k$ número real. Ou seja, $\vec{u}$ e $\vec{v}$ têm a mesma direção se e só se $c=k a$ e $d=k b$.

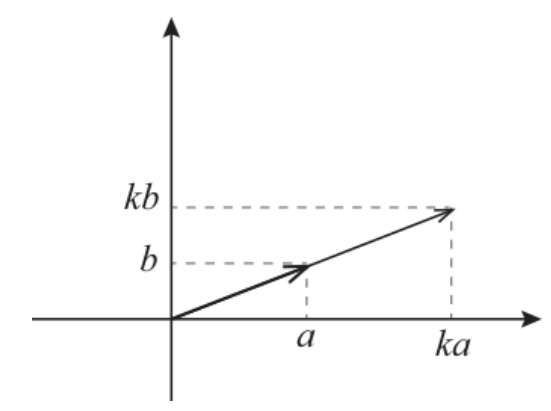

Figura 12 - Esquema vetores com mesma direção

Assim, $\vec{u}$ e $\vec{v}$ têm a mesma direção se e só se $k=c / a=d / b$, se $a$ e $b$ são não nulos, ou melhor, $a d-b c=0$.

Se colocamos as coordenadas de $\vec{u}$ e $\vec{v}$ na primeira linha de uma matriz $2 \times 2$ e as coordenadas de $\vec{u}$ e $\vec{v}$ na segunda linha, então o número $a d-b c$ é o determinante da matriz.

Temos então que o determinante da matriz $\left[\begin{array}{ll}a & b \\ c & d\end{array}\right]$ é zero se e somente se as linhas formam vetores com a mesma direção ou pelo menos uma linha é nula.

Uma propriedade bem interessante e geométrica: Se $\vec{u}$ e $\vec{v}$ não têm a mesma direção, então eles formam um paralelogramo e a área desse paralelogramo é $\mid a d-$ $b c \mid$. Isso pode ser visto na figura abaixo quando calculamos a área do paralelogramo sendo a área do retângulo de lados medindo $a+c$ e $b+d$ menos áreas das figuras internas, ou seja, $(a+c)(b+d)-c d-a b-2 a d=-a d+b c=|a d-b c|$. 


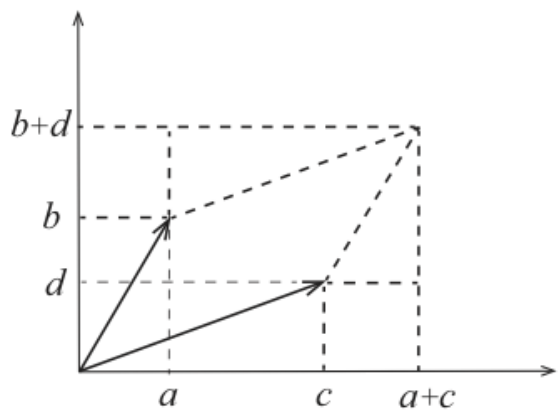

Figura 13 - Esquema cálculo área paralelogramo com dois vetores 